\title{
Supportive Care to Promote Comfort Behavior in Intubated Pediatric Patients
}

\author{
Faten M. Nouh ${ }^{1}$, Maha I. Khalifa ${ }^{2}$, Omayma M. Okby ${ }^{3}$, Amal A. \\ Fathala $^{4}$ \\ ${ }^{I}$ Assistant Lecturer of Pediatric Nursing, ${ }^{2,3}$ Professor of Pediatric Nursing, ${ }^{4}$ Assistant \\ professor of Pediatric Nursing, Faculty of Nursing, Menoufia University
}

\begin{abstract}
Background: Endotracheal intubation (EI) and mechanical ventilation (MV) are frequently used in pediatric patients to optimize gas exchange, breathing and patient comfort while minimizing ventilator-induced lung injury. Comfort management is a priority for patients in all settings. Purpose: To assess nurses' knowledge and practices regarding supportive care to promote comfort behavior in intubated pediatric patients. setting: The study was conducted at pediatric intensive care unit (PICU) in Menoufia University Hospital. Design: A descriptive research was utilized to conduct the study. Sample: A convenient sample of 33 nurses who were working in the previously mentioned setting were included in this study. Instruments: Two instruments were used. Instrument one was a structured interviewing questionnaire sheet. Instrument two was observational checklist for nurses' practice. Results: More than half of nurses (60.6\%) had unsatisfactory knowledge about supportive care to promote comfort behavior in intubated pediatric patients. Also, the majority of nurses had low level of practice regarding supportive care to promote comfort behavior in intubated pediatric patients. Conclusion: Nurses had unsatisfactory level of knowledge and low level of practices regarding supportive care to promote comfort behavior for intubated pediatric patients. Recommendation: The study recommended that there was a serious need for improvement of nurses' knowledge and practices in relation to promoting comfort behavior in intubated pediatric patients.
\end{abstract}

Key words: Supportive Care, Comfort Behavior, Intubated Pediatric Patients.

\section{Introduction}

Endotracheal intubation (ETI) is the placement of a tube into the trachea either orally or nasally for airway management. The utilized tube is a flexible plastic tube placed into the trachea and has a cuff part that can be inflated with air to prevent airway leakage (Lockey et al., 2020).

Endotracheal intubation is done to keep the airway open in order to give oxygen, medicine or anesthesia, support breathing in certain illnesses such as pneumonia, emphysema, heart failure, collapsed lung or severe trauma (Ibarra-Sarlat et al., 2017).

Endotracheal tube forms an open passage in the upper airways. To be able to ventilate the lungs, the air must be free to enter and exit the lungs then; the patient is connected to the mechanical ventilator to provide continuous respiration with an endotracheal tube (Jaber et al., 2018). Mechanical ventilation (MV) in pediatric intensive care unit (PICU) is a major therapeutic modality and a major indication for PICU admission. The frequency of utilizing MV, according to previous studies, varies from $24-60 \%$ of all pediatric intensive care units (Wolfler et al., 2016).

Variations in rates of mechanical ventilation depend on the disease state, severity of illness, PICU size, location, season /time of year, patient population served and political admissions and discharges of PICUs (Farias et al., 2014). For instance, a United States study of 16 PICUs found that mechanical ventilation was required by $30 \%$ of patients admitted to the PICU (Khemani et al., 2019). 
Ventilation rates also vary across countries. A study of six PICUs in Mexico and Ecuador indicated that $64 \%$ of their patients required mechanical ventilation; however, a study of PICUs in Spain reported a similar value to the United States study, of $32 \%$ of patients, admitted to the PICU requiring mechanical ventilation (Farias et al., 2014).

Despite variation in reported ventilation rates in PICUs worldwide, the prevalence of mechanical ventilation in these settings necessitates that clinicians and researchers review the adequacy and effectiveness of current available methods for evaluating and addressing discomfort experienced by mechanically ventilated pediatric patients (Keogh et al., 2015).

In the pediatric intensive care unit (PICU), patients are exposed to both aversive external and internal stimuli which may lead to feelings of discomfort. The bedside of a ventilated child in the PICU is overwhelming and contains bright lights, multiple alarms, frequently changing caregivers, several types of mechanical equipment, medical emergencies, inconsistent sleep/wake cycles and separation from the family and familiar surroundings (Nelson et al., 2019). In fact, PICU noise levels have been shown to be eight times higher than suggested by the American Environmental Protection Agency and the World Health Organization (Milette \& Carnevale, 2013).

Furthermore, children in PICUs undergo five times more painful procedures than children in general pediatric wards (Stevens et al., 2015). A study performed in Europe observed an increase in pain intensity during 12 procedures such as chest tube removal, peripheral intravenous insertion, wound care, mobilization, positioning, respiratory exercises and others.
Among these routine activities, tracheal suctioning was considered the most painful, responsible for certain behaviors (grimace, facial responses and clenched fists) and changes in physiological parameters (Puntillo et al., 2017).

Therefore, it is not surprising that the percentage of children prescribed medication to promote comfort is higher in the PICU than in general pediatric units due to the complexity and invasiveness of the treatments they require in the PICU. Consequently, it is increasingly important that these children receive adequate care to relieve the discomfort they may experience during their stay in the PICU (Arroyo-Novoa et al., 2018).

Although potentially life-saving, MV may create a discomfort experience in patients. Previous studies have estimated that $54 \%$ of patients who received MV experienced discomfort (Nelson et al., 2019). Therefore, nurses and healthcare providers should manage this condition effectively otherwise, it could lead to panic, depression, agitation, delirium and unplanned extubation (Grap et al., 2017).

\section{Purpose}

The purpose of this study was to assess nurses' knowledge and practices regarding supportive care to promote comfort behavior in intubated pediatric patients.

\section{Research questions:}

1) What is nurses' knowledge level regarding supportive care to promote comfort behavior in intubated pediatric patients?

2) What is nurses' practice level regarding supportive care to promote comfort behavior in intubated pediatric patients?

\section{Methods}

Research Design: A descriptive research design was used in this study. 
Research Setting: This study was conducted at pediatric intensive care unit (PICU) in Menoufia University Hospital. It was one large room in the 4th floor. It contained 10 beds.

Sampling: A convenient sample of 33 nurses who were providing direct care to children in the pediatric intensive care unit were included in the current study.

\section{Instruments:}

Two instruments were utilized for data collection:

\section{Instrument one: Structured Interviewing Questionnaire sheet:}

It was designed by the investigator after reviewing related literature. This instrument was divided into two parts:

1) Part one: Social characteristics of studied nurses. It included questions about nurses' age, level of education and years of experience in PICU and attending any previous training courses related to this subject.

2) Part two: Nurses' knowledge about nursing practice guidelines for promoting comfort in intubated pediatric patients. It contained 65 questions about causes of child's discomfort during mechanical ventilation (9 questions), assessment of comfort behavior in mechanically ventilated children (4 questions), positioning (3 questions), suctioning (25 questions), oral care (5 questions), communication (11 questions), environment control (4 questions) and parent's presence and participating in care for intubated children (4 questions).

The Total Scoring System of Nurses' Knowledge:

\begin{tabular}{|l|c|}
\hline Level of knowledge & Score \\
\hline Unsatisfactory $\leq 60 \%$ & $0-78$ \\
\hline Satisfactory >60\% & $79-130$ \\
\hline
\end{tabular}

Instrument two:

Observational checklist for nurses' practice regarding promoting comfort for intubated pediatric patients: - It was developed by the researcher based on review of related literature. It was divided into three parts:

1) Part one: Observational checklist to assess nurses' performance during endotracheal, oropharyngeal and nasopharyngeal suctioning.

Endotracheal suctioning procedure: It included 3 phases (getting ready, during the procedure and after the procedure). The first phase included 4 statements, the second phase included 9 statements and the third phase included 5 statements. The total score for the procedure was 36 points.

\section{Oropharyngeal suctioning} procedure: It included 3 phases (getting ready, during the procedure and after the procedure). The first phase included 4 statements, the second phase included 9 statements and the third phase included 5 statements. The total score for the procedure was 36 points.

\section{Nasopharyngeal suctioning procedure: It included 3 phases (getting ready, during the procedure and after the procedure). The first phase included 4 statements, the second phase included 10 statements and the third phase included 5 statements. The total score for the procedure was 38 points.}

2) Part two: Observational checklist to assess nurses' performance during oral hygiene for intubated children. It included 3 phases (getting ready, during the procedure and after the procedure). The first phase included 4 statements, the second phase included 4 statements and the third phase included 4 statements. The total score for the procedure was 24 points. 
3) Part three: Observational checklist to assess nurse's communication with intubated children. It included all nonverbal communication strategies (11 items) that the nurse can use with intubated children which involved no technology strategies such as gesture, facial expression, eye contact, touch etc., low technology strategies such as drawing, writing, pointing to alphabet board and high technology strategies that use communication devices such as "ICU patient communicator "mobile application.

The Total Scoring System of Nurses' Practices:

\begin{tabular}{|ll|c|}
\hline Properly done & $\geq 60 \%$ & $90-149$ \\
\hline Improperly done & $30 \%$ to $<60 \%$ & $46-89$ \\
\hline Not done & $<30 \%$ & $0-45$ \\
\hline
\end{tabular}

\section{Validity}

For validity assurance, the three instruments were submitted to a jury of five experts including two professors of pediatric nursing and three professors of medical surgical nursing to modify any required items of the instruments. The modifications were done to ascertain their relevance and completeness.

\section{Ethical considerations}

An official approval was obtained from the Ethical Research Committee in the Faculty of Nursing, Menoufia University. A written consent was obtained from nurses who participated in the study. An initial interview was done to inform participants (nurses) about the purpose, benefits of the study and explain that participation in the study was voluntary and the participants could withdraw from the study at any time without penalty.

\section{Pilot study}

It was carried out on 4 nurses (10\% of the sample) after the instruments were developed and before starting the data collection to test the practicability, applicability and to estimate the needed time to fill the instruments. No necessary modifications were done. Therefore, the pilot study was included in the total sample.

\section{Procedure}

1) A written permission to carry out the study was obtained from the director of Menoufia University Hospital after submitting an official letter from the Dean of the Faculty of Nursing at Menoufia University explaining the purpose of the study and methods of data collection.

2) Data collection for this study was conducted for a period of 6 months extending from the 1st of March 2020 to the end of August 2020.

3) The researcher introduced herself to nurses who shared in the study, explained the purpose of the study and methods of data collection.

4) The researchers interviewed every nurse and asked her to fill the structured interviewing questionnaire sheet about supportive care to promote comfort behavior in intubated pediatric patients by using instrument one within 20-30 minutes.

5) Instrument two was used by the researcher for data collection about nurses' practices during providing care for intubated children. Nurses were not informed that they were observed during the morning and afternoon shifts.

\section{Statistical analysis:}

Data was entered and analyzed by using SPSS (Statistical Package for Social Science) statistical package version 22. Graphics were done using Excel program. Qualitative data were presented in the form of frequency distribution tables, number and percentage. 
Results

Table (1): Percentage distribution of studied nurses according to their social characteristics

\begin{tabular}{|c|c|c|}
\hline Social characteristics of studied nurses & N0. & $\%$ \\
\hline $\begin{array}{l}\text { Age }(\text { Years }) \\
20-<25 \\
25-<30 \\
\geq 30 \text { years }\end{array}$ & $\begin{array}{c}18 \\
11 \\
4\end{array}$ & $\begin{array}{l}54.5 \\
33.4 \\
12.1\end{array}$ \\
\hline Mean \pm SD & \multicolumn{2}{|c|}{$22.6 \pm 1.7$ years } \\
\hline $\begin{array}{l}\text { Educational Level } \\
\text { Nursing Diploma } \\
\text { Institute of Nursing tech. } \\
\text { Bachelor }\end{array}$ & $\begin{array}{c}1 \\
27 \\
5\end{array}$ & $\begin{array}{c}3 \\
81.8 \\
15.2\end{array}$ \\
\hline $\begin{array}{l}\text { Experience } \\
<1 \text { year } \\
1-<5 \text { years } \\
5-<10 \text { years } \\
\geq 10 \text { years } \\
\end{array}$ & $\begin{array}{c}6 \\
16 \\
6 \\
5 \\
\end{array}$ & $\begin{array}{l}18.2 \\
48.4 \\
18.2 \\
15.2\end{array}$ \\
\hline $\begin{array}{l}\text { Training courses about promoting comfor } \\
\text { behavior in intubated pediatric patients } \\
\text { No } \\
\text { Total }\end{array}$ & $\frac{33}{33}$ & $\begin{array}{l}100 \\
100\end{array}$ \\
\hline
\end{tabular}

$\underline{\text { Table } 1}$ represented percentage distribution of studied nurses according to their social characteristics. The table showed that more than half of studied nurses $(54.5 \%)$ were between $20-<25$ years. In relation to nurses' qualifications, more than three quarters of studied nurses $(81.8 \%)$ were graduated from technical nursing institute. Regarding years of experience, less than half of studied nurses $(48.4 \%)$ had $1-<5$ years of experience in PICU. Concerning training courses, all of studied nurses (100\%) did not attend any previous training course regarding supportive care to promote comfort behavior in intubated pediatric patients.

Table (2): Levels of nurses' knowledge to promote comfort behavior in intubated pediatric patients.

\begin{tabular}{|l||c||c|}
\hline Knowledge items & No & \% \\
\hline \hline Unsatisfactory knowledge & 20 & $60.6 \%$ \\
Satisfactory knowledge & 13 & $39.4 \%$ \\
\hline \hline Total & 33 & $100.0 \%$ \\
\hline
\end{tabular}

Table 2 illustrated Levels of nurses' knowledge to promote comfort behavior in intubated pediatric patients. This table revealed that more than two thirds of nurses $(60.6 \%)$ had unsatisfactory level of knowledge regarding supportive care to promote comfort behavior in intubated pediatric patients.

Table (3) Distribution of nurses according to their practices that promote comfort behavior in intubated pediatric patients.

\begin{tabular}{|l||c||c|}
\hline Practices items & N0 & \% \\
\hline \hline Not done & 25 & $75.7 \%$ \\
Improperly Done & 5 & $15.3 \%$ \\
Properly Done & 3 & $9.0 \%$ \\
\hline Total & 33 & $100.0 \%$ \\
\hline
\end{tabular}


Table 3 illustrated distribution of nurses according to their practices that promote comfort behavior in intubated pediatric patients. It was clear that the majority of nurses had low level of practice regarding supportive care to promote comfort behavior in intubated pediatric patients.

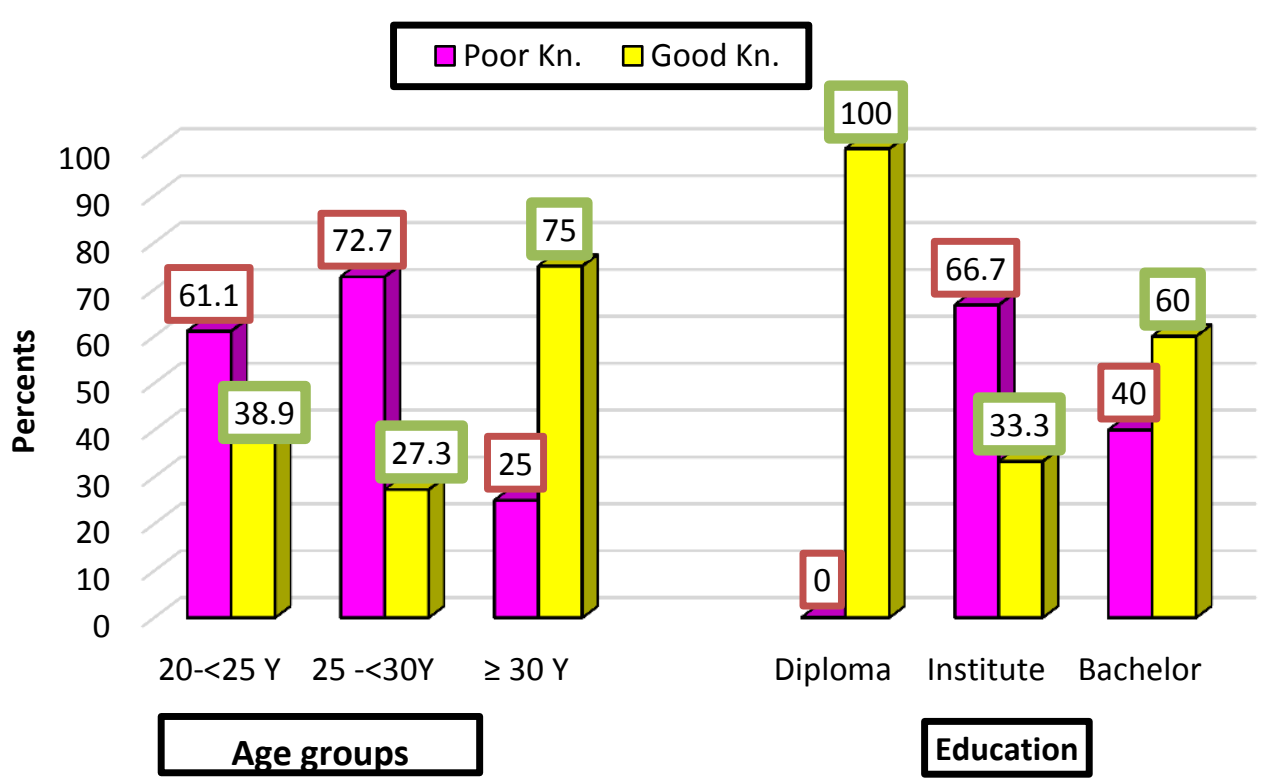

Figure (1): Association between the studied nurses 'age groups and education and their level of knowledge

Figure 1 illustrated association between the studied nurses 'age groups and education and their level of knowledge. The table clarified that there was no statistical significant differences regarding nurses 'age groups and education and their level of knowledge were found.

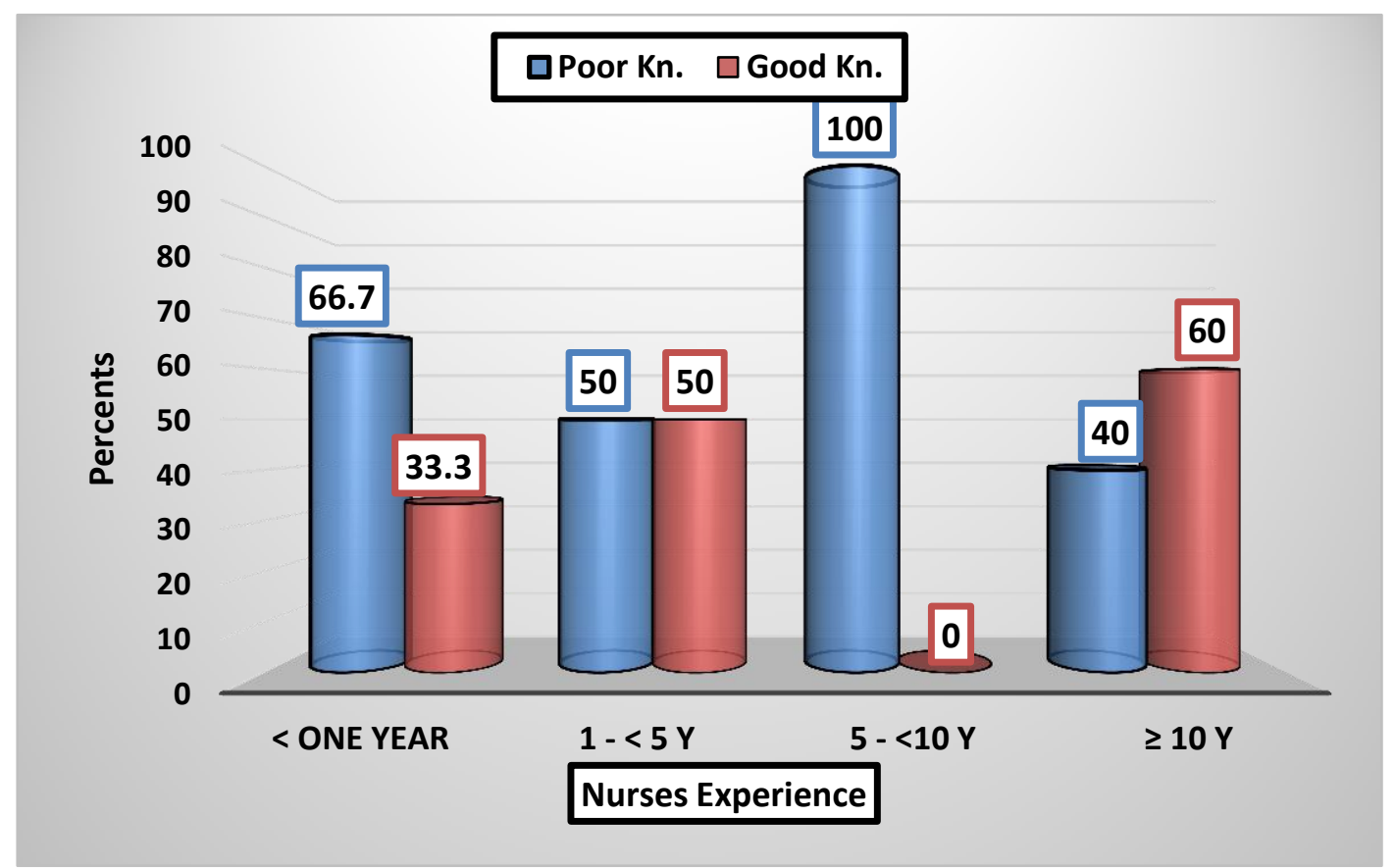

Figure (2): Association between the studied nurses' experiences and their level of knowledge

Figure 2 illustrated association between the studied nurses 'experiences and their level of knowledge. The table clarified that there was no statistical significant differences regarding nurses 'experiences and their level of knowledge were found. 


\section{Discussion}

Comfort in intubated patients receiving mechanical ventilation can be disturbed for many reasons such as pain, anxiety, environmental noises, loneliness which may lead to negative impacts such as panic, depression, agitation and removal of lifesaving medical devices (e.g., endotracheal tubes and intravascular lines), placing both the patient and health care providers at risk (Wang et al., 2015).

Regarding nurses' knowledge about positioning of intubated children, this study revealed that the majority of the studied nurses had incomplete knowledge about positioning of intubated children. This result was consistent with Hesham (2016) who conducted a study about" Assessment of nurses' performance regarding management of patients on mechanical ventilator". It was found that all nurses had unsatisfactory knowledge about positioning mechanically ventilated patients in semi recumbent position. From the researcher's perspective, this could be attributed to all nurses $(100 \%)$ didn't receive any training course regarding this subject.

On the contrary, Gomes (2010) who conducted a study about "Knowledge of intensive care nurses on evidencebased guidelines for the prevention of ventilator associated pneumonia". It was reported that more than two thirds of studied nurses $(68.67 \%)$ answered questions correctly related to positioning and $31.33 \%$ answered incorrectly. Besides, Ahmed \& Abosamra (2015) who conducted a study about "Knowledge of pediatric critical care nurses regarding evidencebased guidelines for prevention of ventilator associated pneumonia (VAP)". They found that more than two thirds of studied nurses $(67.3 \%)$ had correct answers about positioning. This could be attributed to reinforcing the use of semi recumbent positioning in their intensive care units.

Regarding nurses' knowledge about suctioning of intubated children, this study illustrated that the majority of the studied nurses had incomplete knowledge about the majority of items which were related to suctioning. This could be related to nurses' resistance to change, little support from managers, lack of PICU training, lack of ease access to the literature, lack of time to read and understand the literature, lack of access to guidelines and competing workload pressures. This result was consistent with Day et al., (2018) who conducted a research about "An evaluation of a teaching intervention to improve the practice of endotracheal suctioning in intensive care units". They reported low level of knowledge about endotracheal suctioning recommendations among many ICU nurses in London- United Kingdom.

Concerning nurses' knowledge about oral care of intubated children, this study illustrated that the majority of the studied nurses had incomplete knowledge about the majority of items which were related to oral care. This could be related to lack of nurses' education and training. This result was consistent with Abd EL-Aziz (2014) who conducted a research about" Effect of educational program on nurses' knowledge and skills about oral care for traumatized patients". It was found that the majority of nurses had unsatisfactory total knowledge related to oral care procedure before intervention.

On the contrary, Ahmed \& Abosamra (2015) who conducted a study about "Knowledge of pediatric critical care nurses regarding evidence based guidelines for prevention of ventilator associated pneumonia (VAP)" stated that more than two thirds of studied nurses $(65.3 \%)$ reported the correct answer regarding routine oral care for 
ventilated children. In the same context, Said (2019) who conducted a study about" Knowledge and practice of intensive care nurses on prevention of ventilator associated pneumonia at Muhimbili national hospital" reported that ICU nurses' knowledge about oral care was adequate. This could be attributed to receiving training courses regarding this subject.

Regarding nurses' knowledge about environmental control in PICU, this study illustrated that the majority of the studied nurses had incomplete knowledge about the majority of items which were related to environmental control in PICU. From the researcher's perspective, this could be attributed to lack of education and training related to that subject. This result was consistent with Christensen (2015) who conducted a study about "What knowledge do ICU nurses have with regard to the effects of noise exposure in the intensive care unit". It was found that nurses had poor knowledge regarding noise and its psychophysiological effects. In the same context, Johansson et al., (2016) who conducted a study about " Noise in the ICU patient room — staff knowledge and clinical improvements" illustrated that nursing staff had low theoretical knowledge concerning sound and noise in the intensive care unit.

Concerning nurses' knowledge about parental presence and participation in child's care, this study illustrated that the majority of the studied nurses had incomplete knowledge about the majority of items which were related to parental presence and participation in child's care. From the researcher's perspective, this could be attributed to nurses' perception that parental presence and participation in child's care could interfere with their work. Parents gave a lot of comments on their work with the child and asked many questions and managers thought that nurses made parents do their work. Besides, they didn't understand the importance of parental presence and participation in intubated child's care for both parents and children because they didn't receive any training courses related to that subject. On the contrary, Martens et al., (2018) who conducted a study about "Parental participation in care in the pediatric intensive care unit" found that both mothers and nursing staff had a positive attitude with respect to parent's participation in a number of care aspects.

Concerning nurses' practices regarding suctioning of intubated children, this study illustrated that had low level of practice regarding suctioning of intubated children. This could be attributed to the unsatisfactory knowledge of the studied nurses which was reflected negatively on their practices. This result was consistent with Day et al., (2018) who conducted a study about "An evaluation of a teaching intervention to improve the practice of endotracheal suctioning in intensive care units". They reported a considerable lack of knowledge about various aspects of the suctioning procedure accompanied by poor practice. Therefore, they recommended that every nurse, irrespective of the length of intensive care unit experience or qualifications, should receive appropriate teaching to support these guidelines. Also, they need clinical guidelines to be available with them as well as focused practice-based education.

Concerning nurses 'practices regarding oral care of intubated children, this study illustrated that nurses had low level of practice regarding oral care of intubated children. From the researcher's perspective, this could be attributed to lack of supplies needed for oral care, absence of written protocols regarding oral care of 
intubated children. Bedsides, nurses didn't receive any training courses regarding this subject. This result was consistent with Adib-Hajbaghery et al., (2019) who conducted a study about "Intensive care nurses' opinions and practice for oral care of mechanically ventilated patients ". They reported that nearly three quarters $(72 \%)$ of nurses complained of inadequate supplies and equipment needed for oral care of mechanically ventilated patients.

In relation to nurses 'practices regarding communication with intubated children, this study illustrated that all studied nurses didn't use low technology strategies (drawing, writing and point to communication (pictures and alphabet board) or high technology strategies that use communication devices (as mobile applications) to communicate with intubated children. All of them used only no technology strategies (gesture, facial expression, eye contact, touch, head nods, lip reading and voice tone) to communicate with intubated children before intervention. This could be attributed to lack of education and training regarding importance of presence of effective communication with the intubated children and lack of communication materials in PICU. This result was consistent with Radtke et al., (2012), Happ et al., (2014), Magnus\& Turkington (2018) and Boscart (2019). They reported that communication between nurses and mechanically ventilated patients was minimal because nurses perceived communication with intubated patients as a waste of time and time consuming. In availability of skill training workshops and lack of necessary communication materials affect nurses' attitudes poorly toward communication with intubated patients.

\section{Conclusion}

Based on the results of the present study, it was concluded that pediatric nurses had unsatisfactory level of knowledge and low level of practices regarding promoting comfort behavior in intubated pediatric patients and need in-service training to improve their knowledge and practices regarding promoting comfort behavior in intubated pediatric patients.

\section{Recommendations}

Based on study findings and conclusion the following were recommended:

- Ongoing in-service education programs about promoting comfort behavior in intubated pediatric patients should be designed and implemented in pediatric intensive care units to improve pediatric nurses' knowledge and practices.

- Replication of study on a larger sample of nurses obtained from different geographical areas in Egypt.

\section{References}

Abd EL-Aziz, M. A. (2014). Effect of Educational Program on nurses Knowledge and skills about oral care for traumatized patients. AAMJ, 12(1), 25-47.

Adib-Hajbaghery, M., Ansari, A., \& Azizi-Fini, I. (2013). Intensive care nurses' opinions and practice for oral care of mechanically ventilated patients. Indian Journal of Critical Care Medicine: Peerreviewed, Official Publication of Indian Society of Critical Care Medicine, 17(1), 23.

Ahmed, G. E., \& Abosamra, O. M. (2015). Knowledge of Pediatric Critical Care Nurses Regarding Evidence Based Guidelines for Prevention of Ventilator Associated Pneumonia (VAP). Journal of Education and Practice, 6(9), 94-101. 
Arroyo-Novoa, C. M., FigueroaRamos, M. I., Puntillo, K. A., Stanik-Hutt, J., Thompson, C. L., White, C., \& Wild, L. R. (2018). Pain related to tracheal suctioning in awake acutely and critically ill adults: a descriptive study. Intensive and Critical Care Nursing, 24(1), 20-27.

Boscart, V. M. (2019). A communication intervention for nursing staff in chronic care. Journal of Advanced Nursing, 65(9), 1823-1832.

Christensen, M. (2015). What knowledge do ICU nurses have with regard to the effects of noise exposure in the Intensive Care Unit?. Intensive and Critical Care Nursing, 21(4), 199-207.

Day, T., Wainwright, S. P., \& Wilson- Barnett, J. (2018). An evaluation of a teaching intervention to improve the practice of endotracheal suctioning in intensive care units. Journal of clinical nursing, 10(5), 682-696.

Farias, J. A., Frutos, F., Esteban, A., Flores, J. C., Retta, A., Baltodano, A., \& Johnson, M. (2014). What is the daily practice of mechanical ventilation in pediatric intensive care units? A multicenter study. Intensive care medicine, 30(5), 918-925.

Gomes, V. P. (2010). Knowledge of intensive care nurses on evidence-based guidelines for prevention of ventilator associated pneumonia (Doctoral dissertation).

Grap, M. J., Blecha, T., \& Munro, C. (2017). A description of patients' report of endotracheal tube discomfort. Intensive and Critical Care Nursing, 18(4), 244-249.

Happ, M. B., Garrett, K. L., Tate, J. A., DiVirgilio, D., Houze, M. P., Demirci, J. R., \& Sereika, S. M.
(2014). Effect of a multi-level intervention on nurse-patient communication in the intensive care unit: results of the SPEACS trial. Heart \& lung, 43(2), 89-98.

Hesham, S. (2016). Assessment of nurses' performance regarding management of patients on mechanical ventilator. Port Said Scientific Journal of Nursing, 3(1), 161-177.

Ibarra-Sarlat, M., Terrones-Vargas, E., Romero-Espinoza, L., Castañeda-Muciño, G., HerreraLandero, A., \& Núñez-Enríquez, J. C. (2017). Endotracheal Intubation in Children: Practice Recommendations, Insights, and Future Directions. In Bedside Procedures. IntechOpen.

Jaber, S., Amraoui, J., Lefrant, J. Y., Arich, C., Cohendy, R., Landreau, L., ... \& Eledjam, J. J. (2018). Clinical practice and risk factors for immediate complications of endotracheal intubation in the intensive care unit: a prospective, multiplecenter study. Critical care medicine, 34(9), 2355-2361.

Johansson, L., Knutsson, S., Bergbom, I., \& Lindahl, B. (2016). Noise in the ICU patient room-Staff knowledge and clinical improvements. Intensive and Critical Care Nursing, 35, 1-9.

Keogh, S. J., Long, D. A., \& Horn, D. V. (2015). Practice guidelines for sedation and analgesia management of critically ill children: a pilot study evaluating guideline impact and feasibility in the PICU. BMJ open, 5(3), e006428.

Khemani, R. G., Markovitz, B. P., \& Curley, M. A. (2019). Characteristics of children intubated and mechanically ventilated in 16 PICUs. Chest, 136(3), 765-771. 
Lockey, D., Davies, G., \& Coats, T. (2020). Survival of trauma patients who have prehospital tracheal intubation without anaesthesia or muscle relaxants: observational study. Bmj, 323(7305), 141.

Magnus, V. S., \& Turkington, L. (2018). Corrigendum to "Communication interaction in ICU-Patient and staff experiences and perceptions" [Intensive Crit. Care Nurs. 22 (3) (2006) 167-180]. Intensive \& Critical Care Nursing, 4(24), 264.

Martens, F., De Loof, B. S., \& Idrissi, S. (2018). Parental participation in care in the pediatric intensive care unit. International Editorial Advisory Board, 11.

Puntillo, K. A., Max, A., Timsit, J. F., Vignoud, L., Chanques, G., Robleda, G., \& Azoulay, E. (2017). Determinants of procedural pain intensity in the intensive care unit. The Europain ${ }^{\circledR} \quad$ study. American journal of respiratory and critical care medicine, 189(1), 39-47.

Radtke, J. V., Tate, J. A., \& Happ, M. B. (2012). Nurses' perceptions of communication training in the ICU. Intensive and Critical Care Nursing, 28(1), 16-25.
Said, A. T. (2018). Knowledge and practice of intensive care nurses on prevention of ventilator associated pneumonia at Muhimbili national hospital, Dar es Salaam, Tanzania (Doctoral dissertation, Muhimbili University of Health and Allied Sciences).

Stevens, B. J., Abbott, L. K., Yamada, J., Harrison, D., Stinson, J., Taddio, A.,... \& Finley, G. A. (2015). Epidemiology and management of painful procedures in children in Canadian hospitals. Cmaj, 183(7), E403E410.

Wang, Y., Li, H., Zou, H., \& Li, Y. (2015). Analysis of complaints from patients during mechanical ventilation after cardiac surgery: a retrospective study. Journal of cardiothoracic and vascular anesthesia, 29(4), 990-994.

Wolfler, A., Calderoni, E., Ottonello, G., Conti, G., Baroncini, S., Santuz, P., \& SISPE Study Group. (2016). Daily practice of mechanical ventilation in Italian pediatric intensive care units: a prospective survey. Pediatric Critical Care Medicine| Society of Critical Care Medicine, 12(2), 141-146. 